\title{
Siberian Snow Forcing in a Dynamically Bias-Corrected Model $\mathscr{O}$
}

\author{
Nicholas L. Tyrrell, ${ }^{\mathrm{a}}$ AleXey Yu. KarpechKo, ${ }^{\mathrm{a}}$ AND Sebastian Rast ${ }^{\mathrm{b}}$

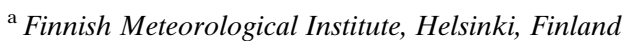 \\ ${ }^{\mathrm{b}}$ Max Planck Institute for Meteorology, Hamburg, Germany
}

(Manuscript received 2 January 2020, in final form 11 August 2020)

\begin{abstract}
We investigate the effect of systematic model biases on teleconnections influencing the Northern Hemisphere wintertime circulation. We perform a two-step nudging and bias-correcting scheme for the dynamic variables of the ECHAM6 atmospheric model to reduce errors in the model climatology relative to ERA-Interim. One result is a significant increase in the strength of the Northern Hemisphere wintertime stratospheric polar vortex, reducing errors in the December-February mean zonal stratospheric winds by up to $75 \%$. The bias corrections are applied to the full atmosphere or the stratosphere only. We compare the response of the bias-corrected and control runs to an increase in Siberian snow cover in October-a surface forcing that, in our experiments, weakens the stratospheric polar vortex from October to December. We find that despite large differences in the vortex strength the magnitude of the stratospheric weakening is similar among the different climatologies, with some differences in the timing and length of the response. Differences are more pronounced in the stratosphere-troposphere coupling, and the subsequent surface response. The snow forcing with the stratosphere-only bias corrections results in a stratospheric response that is comparable to control, yet with an enhanced surface response that extends into early January. The full-atmosphere bias correction's snow response also has a comparable stratospheric response but a somewhat suppressed surface response. Despite these differences, our results show an overall small sensitivity of the Eurasian snow teleconnection to the background climatology.
\end{abstract}

KEYWORDS: Stratospheric circulation; Teleconnections; Stratosphere-troposphere coupling; Stratosphere; Climate models; Model errors

\section{Introduction}

To make accurate seasonal forecasts we need to correctly model both the atmospheric base state - the climatology — and the response to persistent anomalies that can give information about the future state of the atmosphere. A model's response to anomalies can be dependent on the model climatology, meaning that errors in climatology can compound forecasting errors. It has been proposed that Siberian snow cover extent can influence European wintertime conditions via a stratospheric mechanism and thus allow for some seasonal forecasting (Cohen and Fletcher 2007; Butler et al. 2019; Cohen et al. 2007) as follows: an increased Siberian snow extent provides a thermal forcing to the lower atmosphere, resulting in an increase in planetary waves. Planetary waves propagate to the stratosphere and weaken the stratospheric polar vortex. Finally, stratospheric anomalies propagate downward and induce a negative Arctic Oscillation (AO) in the troposphere.

There is evidence for this snow-AO mechanism in observational studies, for both individual years (Cohen et al. 2010; Orsolini et al. 2016; Tyrrell et al. 2019) and analysis of the historical record (Douville et al. 2017; Henderson et al. 2018). However, there is debate around the importance of the snow

Supplemental information related to this paper is available at the Journals Online website: https://doi.org/10.1175/JCLI-D-190966.s1.

Corresponding author: Nicholas L Tyrrell, nicholas.tyrrell@ fmi.fi cover extent for wave forcing (Henderson et al. 2018; Kretschmer et al. 2016). Increased snow cover is often associated with the warm Arctic-cold Siberia pattern and Ural blocking (Tyrlis et al. 2019), which can also lead to enhanced wave flux and weakening of the polar vortex (Peings 2019). The snow-AO mechanism has been demonstrated in climate models when a large snow anomaly is introduced into the model; however, the response of the model tends to be weaker and occurs on shorter time scales than in observations (Fletcher et al. 2007; Tyrrell et al. 2018). The timing of the European response to Siberian snow is an important aspect for seasonal prediction, and while some observational studies show a connection between October snow conditions and January surface conditions (e.g., Cohen et al. 2007; Furtado et al. 2015), modeling studies show the response to October snow anomalies occurs in November/December (Fletcher et al. 2007; Orsolini et al. 2016; Tyrrell et al. 2018). Tyrrell et al. (2019) also showed similarly short timing in a case study of 2016 autumn, where a large October Siberian anomaly led to a weakened November vortex, and propagation to the surface in late November/early December. In addition, the mechanism has not been demonstrated in models with freely evolving snow cover, such as the CMIP3 or CMIP5 models (Hardiman et al. 2008; Furtado et al. 2015).

If a robust Siberian snow-AO connection exists, then successful simulation of the process requires a number of steps to be modeled sufficiently well, beginning with the snow cover properties. The snow extent anomaly increases the albedo of the surface and cools the near-surface air temperatures. Gong et al. (2002) stated that the snow depth does not significantly affect the near-surface cooling; indeed, some model experiments simulate 
the snow-induced cooling by only changing the surface albedo (Allen and Zender 2010). Hardiman et al. (2008) and Furtado et al. (2015) showed that in the CMIP3 and CMIP5 models the snow extent variability was well below observed, which they theorized as a reason for the lack of the snow-AO mechanism in these models. The low snow extent variance is dealt with in most modeling studies by artificially adding a snow anomaly over a large area (Gong et al. 2002).

The next step in modeling the snow-AO connection is the enhanced upward wave flux from the troposphere to the stratosphere, and the stratospheric wave-mean flow interaction, which weakens the polar vortex. As outlined in Fletcher et al. (2009) the cooling due to snow leads to domed isentropic surfaces, which generate an upward-propagating Rossby wave. Smith et al. (2010) varied the position of a surface cold anomaly to show the importance of the latitudinal location of the induced anomalous wave and the climatological stationary wave for constructive interference to occur, which was crucial for a strong zonal mean response. The examination of constructive interference was extended by Smith et al. (2011), who found that the lag between October snow anomalies and wave activity was caused by initially unfavorable conditions for constructive interference, which transitioned in mid-November to favor constructive interference, a process not captured in the CMIP3 models.

Regarding vortex weakening by tropospheric wave forcing, there is still discussion about the relative importance of anomalous tropospheric waves, compared to the receptiveness of the stratosphere to the climatological tropospheric waves. The importance of the stratospheric communication layer, just above the tropopause, is stressed in Birner and Albers (2017). Work by de la Cámara et al. (2017) finds the 100- and 300-hPa heat flux to be suitable proxies for troposphere to stratosphere wave flux, and they conclude that model biases may affect predictability, due to the importance of the stratosphere in regulating wave propagation. Likewise, Tripathi et al. (2016), in a multimodel study of the predictability of a specific sudden stratospheric warming (SSW), suggest that biases in stratospheric winds may affect the predictive ability of a model.

Finally, we consider the downward propagation of a weakened vortex (i.e., Baldwin and Dunkerton 2001) from the perspective of climatological biases and the preconditioning of the troposphere to a stratospheric signal. Gerber et al. (2009) show that the surface response to a stratospheric anomaly is dependent on the tropospheric variability in model experiments. Karpechko et al. (2017) define downward- and nondownward-propagating SSWs and find the lower-stratospheric anomalies to be most significant for predicting the tropospheric response, and White et al. (2019) use a large number of SSW events $(\sim 950)$ and found evidence of differences in the tropospheric precursors, both zonal mean and regional, between downward- and non-downward-propagating SSWs.

In this study we will test the response of the model to perturbations while bias-correcting the climatology. Nudging techniques have been used for reducing biases, for example through downscaling techniques (Eden et al. 2012; SchubertFrisius et al. 2017). The bias correction technique we have used in this study differs in that it allows the model to freely respond to perturbations, rather than being tightly constrained to the nudging dataset. The bias correction technique was demonstrated by Kharin and Scinocca (2012) and involves a training stage where the dynamic variables of the model are nudged toward reanalysis data. The nudging tendencies are recorded at each time step and used to create a climatology of tendencies, which represents the inherent model bias. During the bias correction step the climatology of tendencies are subtracted from the model, thereby reducing the bias. The technique has been used by Simpson et al. (2013a,b) to study the impact of jet latitude bias and the Antarctic polar vortex breakdown on the persistence of the southern annular mode. A similar bias correction technique has also been used by Chang et al. (2019) with atmosphere-only and coupled models. They study how reduced global atmospheric biases affect a model's climatology, variability, and forecast skill, focusing on North America. They found an improvement in the simulation of the North Pacific jet and rainfall climatology, and a modest improvement in seasonal forecast skill. Schubert et al. (2019) investigated the geographical sources of model biases by systematically applying bias corrections to different regions around the world, and found that bias-correcting the atmosphere over the Tibetan Plateau provided the largest improvements for North American climate.

All the various steps in the snow-AO mechanism rely on the interaction between an anomaly and the background climatology, an interaction that will be modulated by the location, strength, and timing of both the anomaly and background state. Hence, it seems likely that biases in a model's climatology will affect the simulation of the snow-AO mechanism.

In section 2 we outline the bias correction method and the model experiments, and in section 3 the improvements to the mean climate are shown. Section 4 discusses the model response to a surface perturbation with the bias-corrected atmosphere, and a discussion and conclusions are given in section 5 .

\section{Methods}

\section{a. Model details}

All experiments use the ECHAM6 spectral atmospheric model (Stevens et al. 2013), run with a horizontal truncation of T63 and 95 vertical levels with a model top at $0.02 \mathrm{hPa}$. For the training step of the bias correction we use observed SSTs and sea ice from the HadISST dataset (Rayner et al. 2003) for the years 1979-89. All other experiments use annually repeating climatological monthly SSTs and sea ice. We compare atmospheric fields of our model to the ERA-Interim dataset (Dee et al. 2011).

\section{b. Bias correction technique}

The bias correction technique follows that described in Kharin and Scinocca (2012, hereinafter KS12). It is a two-step process. The bias correction terms are calculated during a nudged "training stage" and then they are applied to a new model run. For the training stage the three model variables are nudged toward ERA-Interim; divergence, vorticity, and log of surface pressure. The model is nudged for 10 years toward 
TABLE 1. Control and forcing experiments.

\begin{tabular}{lcc}
\hline \hline \multicolumn{1}{c}{ Expt name } & Bias corrections & Snow anomaly \\
\hline CTRL & None & None \\
CTRL_SNOW & None & October, $40^{\circ}-80^{\circ} \mathrm{N}, 60^{\circ}-140^{\circ} \mathrm{E}$ \\
FullBC & Divergence, vorticity, log surface & None \\
FullBC_SNOW & pressure; $850-2.6 \mathrm{hPa}$ & October, $40^{\circ}-80^{\circ} \mathrm{N}, 60^{\circ}-140^{\circ} \mathrm{E}$ \\
StratBC & Divergence, vorticity, log surface & pressure; $850-2.6 \mathrm{hPa}$ \\
StratBC_SNOW & Divergence, vorticity; $100-2.6 \mathrm{hPa}$ & None \\
& Divergence, vorticity; $100-2.6 \mathrm{hPa}$ & October, $40^{\circ}-80^{\circ} \mathrm{N}, 60^{\circ}-140^{\circ} \mathrm{E}$ \\
\hline
\end{tabular}

ERA-Interim to calculate the bias correction. Longer nudging periods were also tested but 10 years was found to be sufficient to significantly reduce the biases. The technique also allows for the temperature to be nudged and biascorrected; however, for the current setup our model became unstable when bias-correcting the temperatures. The instability caused by the temperature bias corrections appeared to be related to our model's high vertical resolution in the stratosphere, and we prioritized a high vertical resolution rather than bias-correct the temperatures for this study. This type of nudging and bias-correcting is well suited to spectral models such as ECHAM, since it is possible to nudge, for example, only the large horizontal scales, leaving smallerscale variability to adjust naturally. Following KS12 only spectral wavenumbers below $n=21$ are nudged and biascorrected. The minimum wavenumber of $n=21$ is somewhat arbitrary, although it represents the synoptic scale. Our aim being to reduce the large-scale spatial biases and monthly to annual biases in time, hence, nudging smaller wavenumbers is unlikely to improve the biases we are interested in. The strength of the nudging is controlled by the nudging relaxation time scale $\tau$ and is different for each variable. The relaxation time scales are divergence, $\tau=48 \mathrm{~h}$, vorticity, $\tau=24 \mathrm{~h}$, and $\log$ surface pressure, $\tau=24 \mathrm{~h}$. These parameters were found experimentally to minimize the bias. The model is run for 10 years toward ERA-Interim between 1979 and 1989, and the nudging tendencies are recorded every $6 \mathrm{~h}$. Each calendar day for the 10 years is combined to create an annual cycle of mean nudging tendencies. The annual cycle is then smoothed in time with a Gaussian filter ( $\sigma=25$ days $)$. The magnitude of the nudging tendencies depends on the deviation of the model away from the reference state, in this case ERA-Interim. Thus, the resultant field is an annual representation of the inherent bias in the model's winds and pressure field.

In the second step this bias correction field is reintroduced to the model as an additional tendency term at each time step. In the nudging step the model is tightly constrained toward the reference state, and thus the model is unable to respond to any external forcings. In contrast, the bias correction terms are independent of the current model state, which allows the model to respond to forcings and have internal variability, while still reducing errors in the mean state climate. Hence, the bias correction terms are applied to the model for the entire length of the runs, including for the runs with perturbed surface properties. The response that is seen occurs within the improved climatology, and the bias corrections remain the same for the perturbed and nonperturbed runs.

The bias corrections were applied to the troposphere and stratosphere (FullBC experiment; see details in Table 1), or the stratosphere only (StratBC). Following KS12 we do not nudge the model's surface boundary layer; the nudging begins at approximately $850 \mathrm{hPa}$. The upper limit of nudging was limited by the vertical resolution of the ERA-Interim data. Above the stratosphere the model has a greater vertical resolution than ERA-Interim, so the model was not nudged above $\sim 2.6 \mathrm{hPa}$. The vertical range of the bias corrections in the troposphere and stratosphere (i.e., FullBC and FullBC_SNOW; see Table 1) was the same as the vertical range of the nudging. Those same bias correction terms were used for the stratosphere-only bias corrections (StratBC and StratBC_SNOW), but they were set to zero in the troposphere and linearly increased over five model levels from approximately 100 to $70 \mathrm{hPa}$.

\section{c. Forcing experiments}

The response of the bias-corrected model was tested with forcing experiments. A snow anomaly is prescribed over $40^{\circ}-$ $80^{\circ} \mathrm{N}, 60^{\circ}-140^{\circ} \mathrm{E}$, whereby snow cover of $100 \mathrm{~kg} \mathrm{~m}^{-2}$ snow water equivalent was added to the surface during October. The snow cover was added instantaneously on 1 October, as previous testing with gradually increasing snow showed no significant differences. The snow cover was then allowed to evolve freely after October, similar to the experiments described in Tyrrell et al. (2018). The amount of snow and areal extent are not intended to realistically model specific years or events, but intended as an amplified forcing to test the response of the atmosphere to this specific surface forcing. Table 1 shows the six experiments, each 100 years long, all using HadISST climatological SSTs and sea ice. One limitation of this experimental setup is that extended Siberian snow cover is often associated with the warm Arctic-cold Siberia pattern, and the associated pressure field, which may contribute to the snow anomaly (Cohen et al. 2014). The larger context within which a snow anomaly usually occurs should be considered when comparing directly to observations; however, artificially adding snow still allows us to test the importance of this specific forcing and isolate atmospheric 


\section{DJF zonal $u$ and surface pressure}
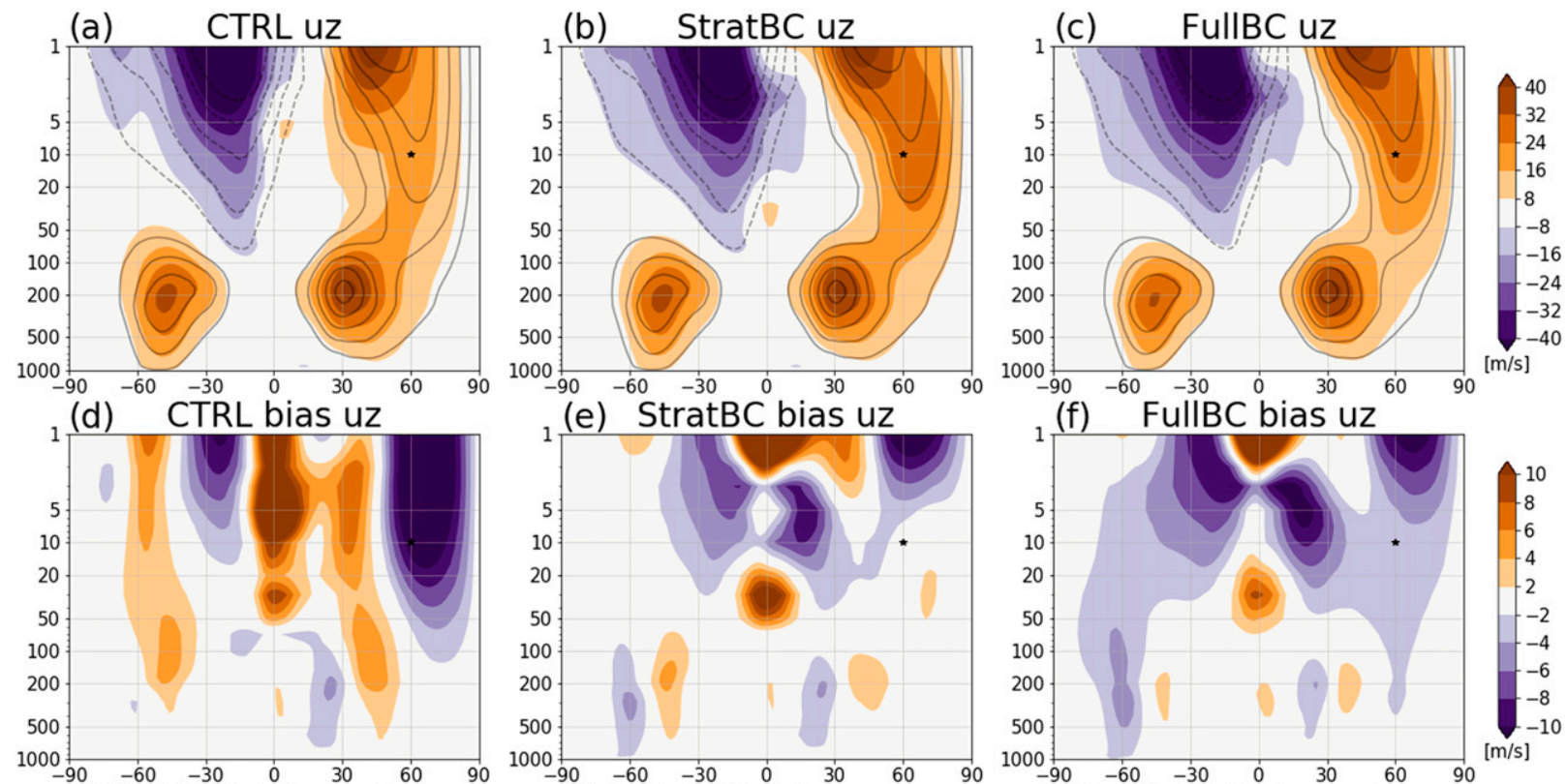

(g) CTRL bias psl

(h) StratBC bias psl

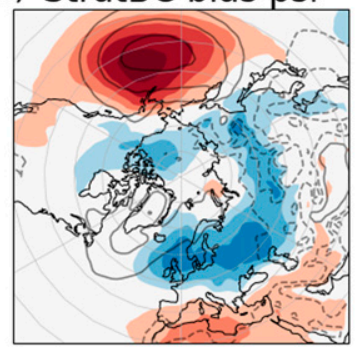

(i) FullBC bias psl

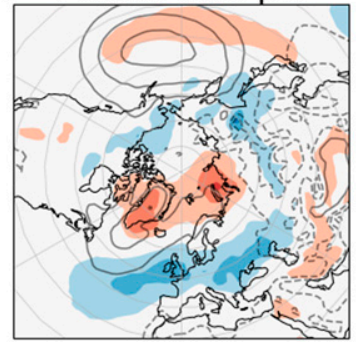

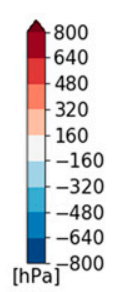

FIG. 1. Bias corrections in the ECHAM6 model. (top) DJF zonal-mean zonal winds (contours are for ERA-Interim 1979-2016; shading indicates the model) for (a) CTRL, (b) StratBC, and (c) FullBC. (middle) Biases in zonal-mean zonal wind (model - ERA-Interim) for (d) CTRL, (e) StratBC, and (f) FullBC. The black star in (a)-(f) indicates the location of the $\mathrm{uz}_{60 \mathrm{~N}}$ 10-hPa index. (bottom) Biases in surface pressure (model - ERA-Interim) for (g) CTRL, (h) StratBC, and (i) FullBC. Contours show ERA-Interim climatology for 1979-2016.

response to snow anomalies from the pre-existing conditions that are not a part of the response.

\section{Bias corrections}

Our perturbation experiments are expected to influence the wintertime climate via the $\mathrm{NH}$ polar stratospheric vortex; hence, we focus on the biases in that region $\left(60^{\circ}-90^{\circ} \mathrm{N}, 100-1\right.$ $\mathrm{hPa}$ ). The improvements in the model climatology due to the bias corrections are demonstrated in Fig. 1. Figures 1a-c show the DJF zonal-mean zonal wind (uz) for the CTRL, FullBC, and StratBC. The biases (i.e., CTRL - ERA-Interim) are shown in Figs. 1d-f. The CTRL run (Figs. 1a,d) has a strong negative bias in the $\mathrm{NH}$ polar vortex region, implying the wintertime polar vortex is too weak. At $10 \mathrm{hPa}, 60^{\circ} \mathrm{N}$, the bias in DJF uz is $10.8 \mathrm{~m} \mathrm{~s}^{-1}$. When the bias corrections are applied to the troposphere and stratosphere (FullBC; Figs. 1c,f) the bias in DJF uz at $10 \mathrm{hPa}, 60^{\circ} \mathrm{N}$ reduces from 10.8 to $2.7 \mathrm{~m} \mathrm{~s}^{-1}$, a $75 \%$ reduction in the bias. The bias is, somewhat unexpectedly, further reduced to less than $1 \mathrm{~m} \mathrm{~s}^{-1}$ for the stratosphereonly bias corrections (StratBC; Figs. 1b,e). The difference between the FullBC and StratBC DJF biases is elucidated in Fig. 2 in the daily zonal-mean zonal winds at $60^{\circ} \mathrm{N}$ at $10 \mathrm{hPa}$ $\left(\mathrm{uz}_{60 \mathrm{~N}}\right)$. From October to mid-January during the growth phase the vortices in FullBC and StratBC are slightly weaker than ERA-Interim, and then during the decay phase (January to February) the StratBC vortex is stronger than ERA-Interim. Hence, the reduced seasonal mean bias for StratBC does not indicate an overall improvement in the daily polar vortex climatology relative to FullBC, but rather an overcompensation during the decay phase.

The biases in surface pressure (Figs. 1g-i) of the CTRL run show a too weak Aleutian low and too low pressure over northern Europe. The RMSE for the DJF surface pressure north of $20^{\circ} \mathrm{N}$ for CTRL is $2.33 \mathrm{hPa}$. This bias is largely reduced in FullBC, which includes bias correction of the tropospheric 

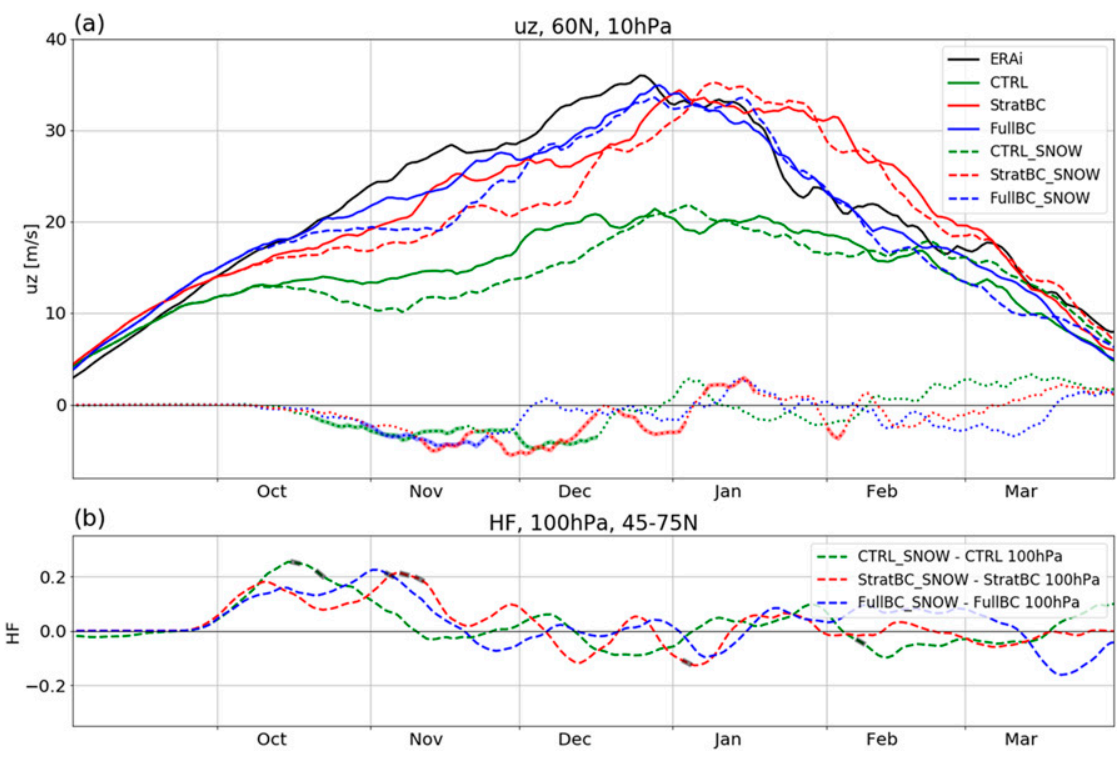

FIG. 2. (a) Daily zonal-mean zonal wind $\left(\mathrm{m} \mathrm{s}^{-1}\right)$ at $60^{\circ} \mathrm{N}, 10 \mathrm{hPa}$ for ERA-Interim 1979-2016 (black line), the control runs (solid lines), and snow anomaly runs (dashed lines) and differences due to snow (dotted lines; colored shading indicates significant difference, $p<0.05$ ). (b) Difference between control and snow anomaly of $\mathrm{HF}$ at $100 \mathrm{hPa}$ (dashed lines), $45^{\circ}-75^{\circ} \mathrm{N}$, normalized by standard deviation of control runs (no units). Shading shows significance: $p<$ 0.05 . Daily values smoothed with Gaussian window filter, $\sigma=7$ days.

pressure field. The RMSE for FullBC is $1.43 \mathrm{hPa}$, a reduction of $38 \%$ compared to CTRL. The tropospheric pressure fields are not bias-corrected in StratBC, but there is still some reduction of the bias. The StratBC RMSE is $2.17 \mathrm{hPa}$, a modest decrease of $7 \%$ compared to the CTRL run, indicating the improved stratospheric climatology has a minor yet favorable influence on the troposphere.

\section{Model response with improved climatology}

\section{a. Evolution of the tropospheric to stratospheric response to a snow anomaly}

We now look at how the model responds to a snow anomaly within the different climatologies. In Fig. 2 a we use $\mathrm{uz}_{60 \mathrm{~N}}$ as a measure of the strength of the vortex. The solid lines in Fig. 2 show the $\mathrm{uz}_{60 \mathrm{~N}}$ for the control runs, the dashed lines show the snow anomaly runs, and the dotted line shows the difference due to the snow anomaly with the colored shading indicating a significance difference. The snow anomaly is applied during October, and for all experiments the daily $\mathrm{uz}_{60 \mathrm{~N}}$ weakens from around the middle of October. Despite a difference in $\mathrm{uz}_{60 \mathrm{~N}}$ of up to $10 \mathrm{~m} \mathrm{~s}^{-1}$ between the bias-corrected and control runs, the magnitude of the weakening of $\mathrm{uz}_{60 \mathrm{~N}}$ due to the snow anomaly is very similar across all experiments. However, there are differences in the persistence of the weakened vortex. In the FullBC_SNOW runs the vortex remains weaker until the end of November, which is the shortest period of weakening. The vortex in the CTRL_SNOW run remains weak until midDecember, and then the StratBC_SNOW vortex appears to persist into early January; however, even with 100-yr-long run there is still a lot of intraseasonal variability in the climatological mean time series. Given that the bias correction terms tend to strengthen the vortex, one may expect that the weakened vortex in the FullBC_SNOW run will recover more quickly than the CTRL_SNOW run, since the bias correction terms are constantly strengthening the vortex regardless of the snow anomaly. However, the persistent weak vortex in the StratBC_SNOW run indicates that a weak vortex can persist with the bias corrections. Overall, the $\mathrm{uz}_{60 \mathrm{~N}}$ response to a snow anomaly between the different climatologies is similar, showing that the magnitude of vortex weakening due to an imposed surface anomaly is not dependent solely on the vortex strength.

A Siberian snow anomaly is expected to influence the stratosphere via anomalous vertical planetary wave activity flux. To investigate the time evolution of the wave forcing we look at the normalized values of the zonal-mean meridional eddy heat flux $(\mathrm{HF})$ at $100 \mathrm{hPa}, 45^{\circ}-75^{\circ} \mathrm{N}$, a proxy for the vertical component of the Eliassen-Palm flux (Newman et al. 2001). We also looked at the $\mathrm{HF}$ at $300 \mathrm{hPa}$, following de la Cámara et al. (2017), who noted that HF at $300 \mathrm{hPa}$ may be a better proxy for troposphere to stratosphere wave activity flux; however, we did not find any significant HF anomalies at $300 \mathrm{hPa}$ (not shown). In Fig. 2b we see the anomalous HF for the three climatologies, weighted with the standard deviation of the runs without the snow anomaly. There is high variability in the HF so that even with a large surface forcing in October there is little to no significance at $100 \mathrm{hPa}$ (at $p<0.05$ ), but we see values up to $\sim 20 \%$ of the standard deviation in October and November. We note that the maximum amplitudes of HF are 
(a) Eddy Z CTRL anom, Oct
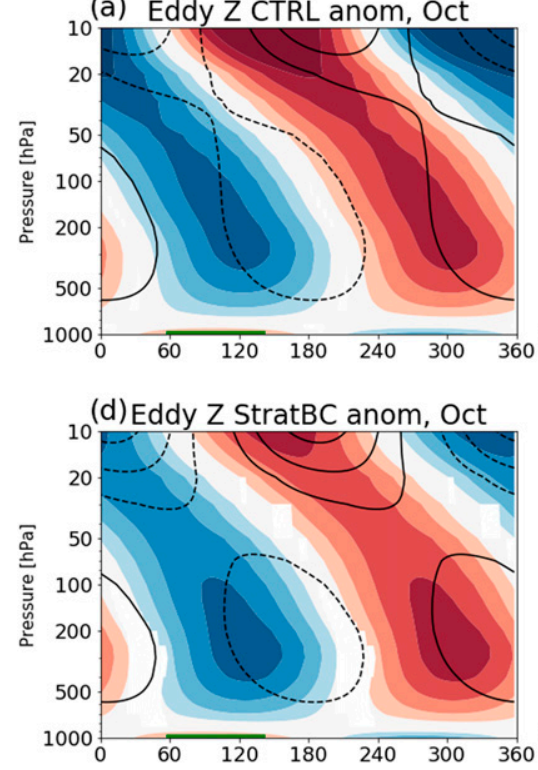

(g) Eddy Z FullBC anom, Oct
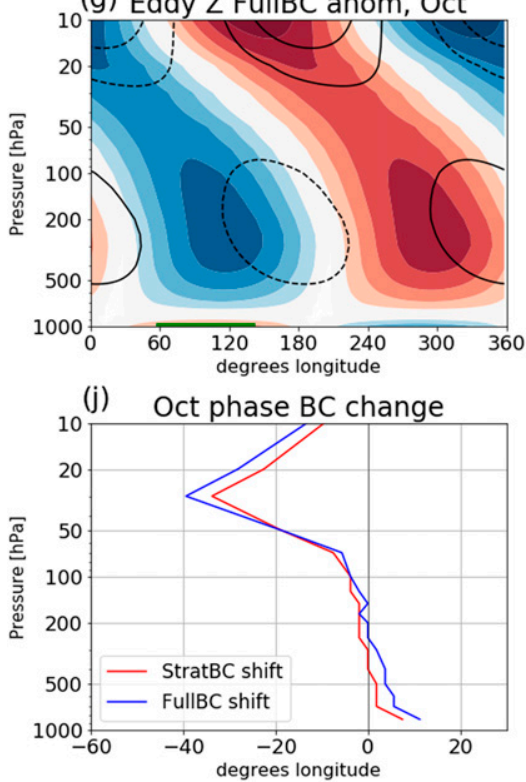

(b) Eddy Z CTRL anom, Nov

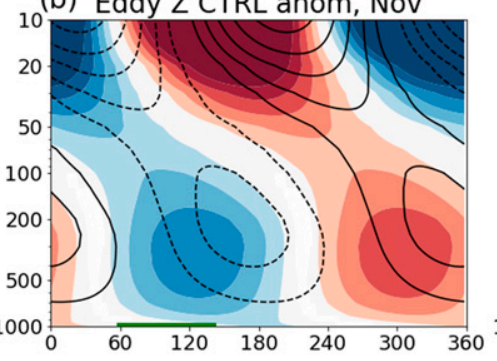

(e)Eddy Z StratBC anom, Nov

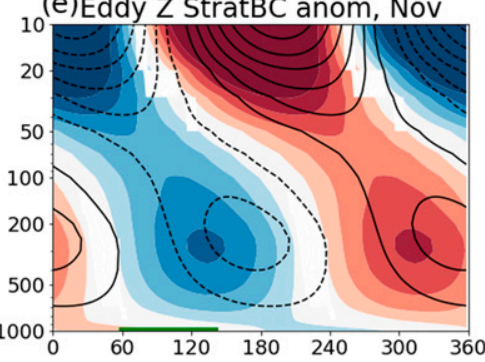

(h) Eddy Z FullBC anom, Nov

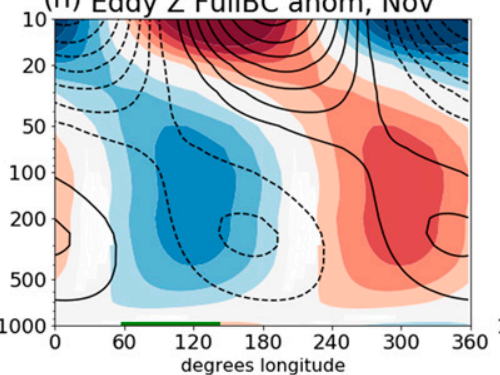

(k) Nov phase BC change

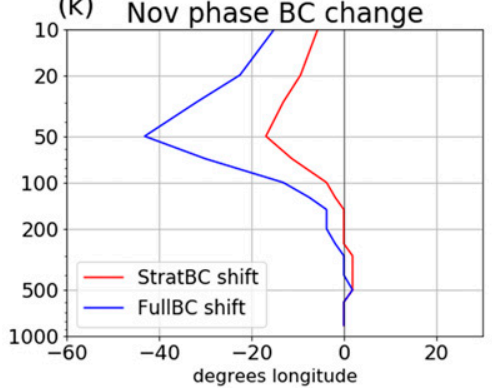

(c) Eddy Z CTRL anom, Dec
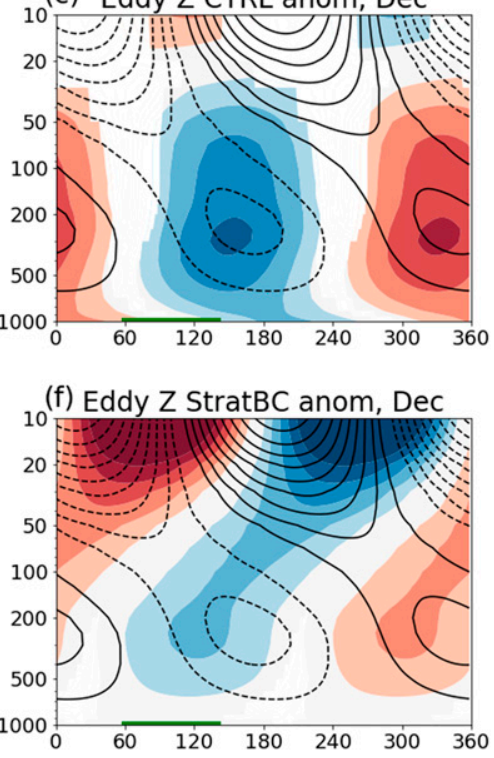

(i) Eddy Z FullBC anom, Dec
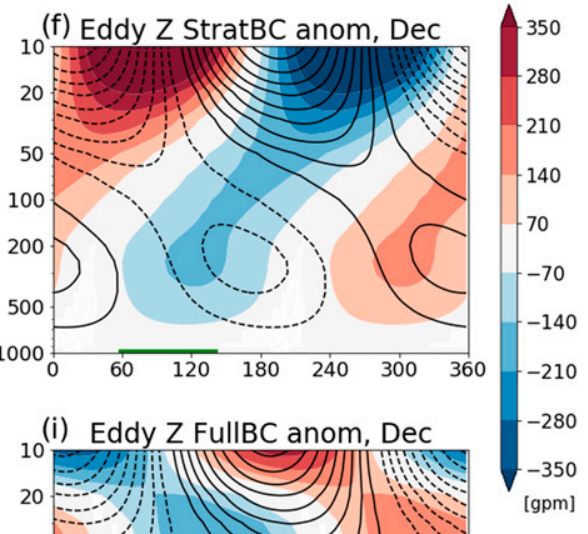

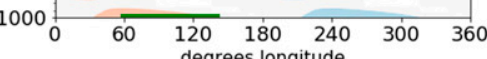

FIG. 3. Monthly wavenumber-1 eddy geopotential height $40^{\circ}-70^{\circ} \mathrm{N}$, snow anomalies (shading; values masked for significance at $p<0.05$ level), and climatology (contours) for (left) October, (center) November, and (right) December for (a)-(c) CTRL, (d)-(f) StratBC, and (g)-(i) FullBC. (bottom) The longitudinal phase shift in the wave-1 climatology due to bias corrections in the control experiments (i.e., the StratBC - CTRL difference, and FullBC - CTRL difference) for October-December.

similar between the different climatologies, but there are differences in the timing of the maximum amplitude. The time variations between the climatologies concur with $\mathrm{uz}_{60 \mathrm{~N}}$ anomalies. The HF in the CTRL experiment has two peaks in mid-October and early December. The $\mathrm{uz}_{60 \mathrm{~N}}$ anomalies integrate the wave forcing, and thus there is a more constant weakening of the winds from October to December, and the second peak likely causes the vortex weakening to continue into December. The HF in FullBC peaks only once in late October/early November, and without additional wave forcing the vortex strengthens in December. The $\mathrm{HF}$ in the StratBC experiment is weak during October before peaking in November, which results in less vortex weakening in October. However, the HF anomaly remains positive for all of October, November, and early December, leading to a significantly weakened vortex throughout November and December. The geographical location of the anomalous wave forcing was checked using the vertical component of the Plumb flux (Plumb 1985) at $100 \mathrm{hPa}$, shown in Fig. S1 in the online supplemental 


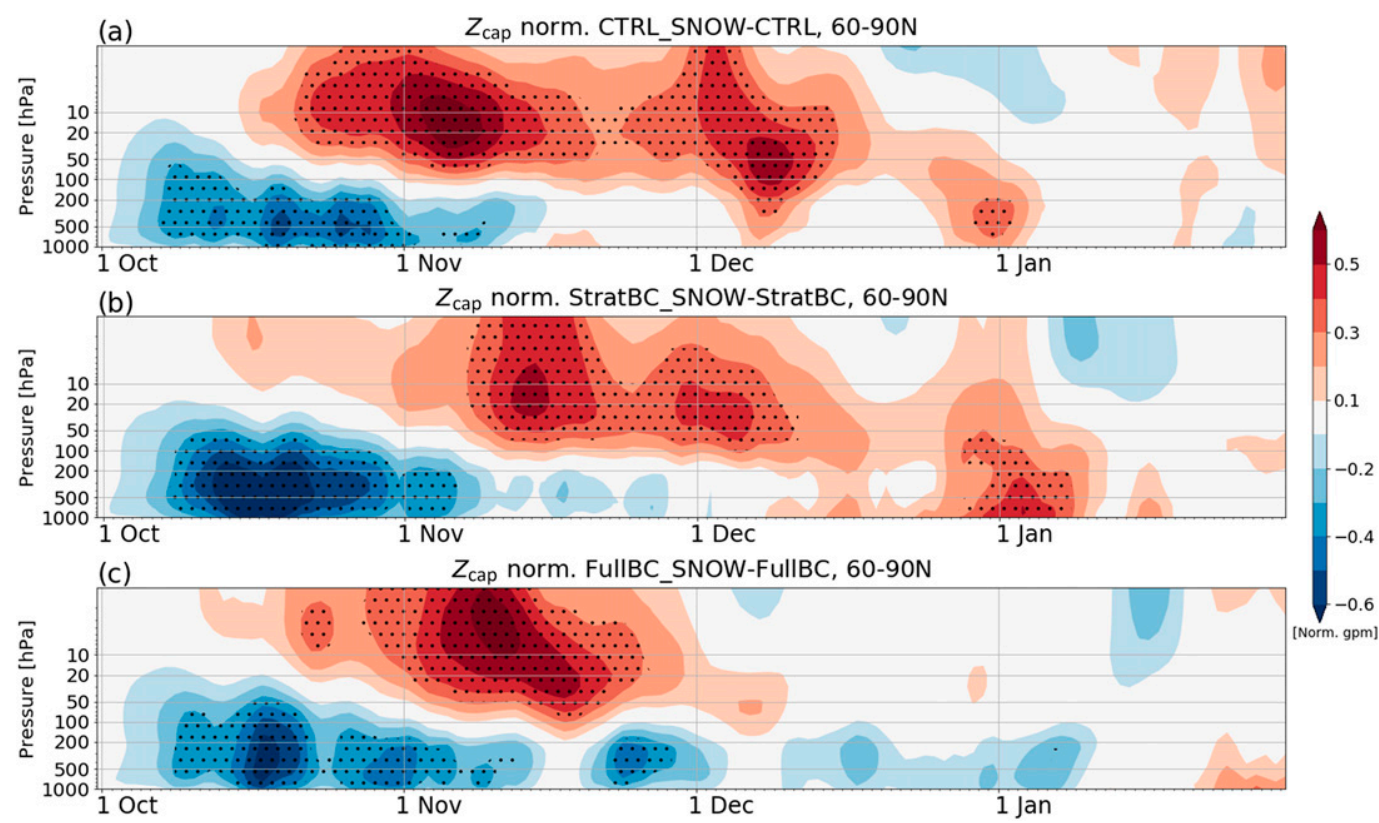

FIG. 4. Daily $Z_{\text {cap }}$ response due to snow anomaly, normalized by standard deviation at each pressure level, for (a) CTRL_SNOW - CTRL, (b) StratBC_SNOW - StratBC, and (c) FullBC_SNOW - FullBC. Stippling indicates significant differences between the snow and control runs at $p<0.05$.

material. In October and November the snow-induced anomalous vertical flux amplifies the climatological flux for all three experiments, particularly above eastern Russia, indicating the increase in HF is geographically collocated with the snow anomaly.

Tyrrell et al. (2019) showed that Siberian surface forcing of the stratosphere is related to anomalous wavenumber 1 and associated vertical wave flux, and in Fig. 3 we diagnose the surface-forced wave structures by looking at the monthly wavenumber-1 eddy geopotential height, averaged over the latitude band $40^{\circ}-70^{\circ} \mathrm{N}$. For all experiments in October we see the characteristic westward-tilting wave- 1 structure, which is associated with upward-propagating waves. The anomalous waves are largely superimposed on the climatological waves, leading to constructive interference. Smith et al. (2010) found the location of a surface snow anomaly relative to the climatology is important for troposphere to stratosphere wave activity, stating that when the anomalous and climatological waves are in phase and the anomaly is relatively small compared to the climatological wave, then linear interference will occur. Therefore, changes in the location of the climatological waves (i.e., due to bias corrections in our experiments) could be the cause of differences between our experiments. We test how the bias corrections have affected the phase of the climatological wavenumber 1 by comparing the phase as a function of altitude of the StratBC and FullBC waves with the CTRL run (Figs. 3j-1). In the troposphere there are only minor changes to the longitudinal position due to the bias corrections. There are larger shifts in the stratosphere, up to $40^{\circ}$ at some levels. Likewise, the phase of the anomalous wavenumber 1 in the snow forcing experiments was similar between all experiments in the troposphere (not shown). Thus, differences in wave interference due to longitudinal shifts in the climatological or anomalous wave should not be expected to cause a different atmospheric response between our experiments.

\section{b. Stratosphere-to-troposphere downward coupling}

The stratospheric wind response to the snow forcing shows some differences between the climatologies (Fig. 2a). Now we investigate the downward propagation and resultant surface response by looking at the daily polar cap $\left(60^{\circ}-90^{\circ} \mathrm{N}\right)$ geopotential height $\left(Z_{\text {cap }}\right)$. In Fig. 4 a weak polar vortex is indicated by a positive (red) geopotential height anomaly above $100 \mathrm{hPa}$. For all three climatologies the stratospheric response to the October snow anomaly peaks in mid-November, with the weakened FullBC_SNOW vortex recovering by December. There are interesting differences in the tropospheric response. For all runs the snow anomaly induces a positive Arctic Oscillation (AO; negative geopotential height anomaly) signal at the surface during October, and which lasts into November. In the CTRL_ SNOW run (Fig. 4a) there is a downward propagation from the stratosphere to the troposphere during December, resulting in a weak negative AO signal at the surface. In the FullBC_ SNOW run (Fig. 4c) the positive AO signal continues through November, by which stage the stratospheric anomalies are weakening and there is no downward propagation. In contrast to this, in the StratBC_SNOW run (Fig. 4b) the positive AO weakens during November, similar to the CTRL_SNOW run, and then there is downward propagation, which leads to a strong negative AO signal at the surface which persists into early January. Focusing on the period from 15 December15 January we find a significant difference in the averaged 1000-hPa polar cap geopotential height response to snow forcing 
$1000 \mathrm{hPa} Z_{\text {cap }}$ response 15 th Dec-15th Jan
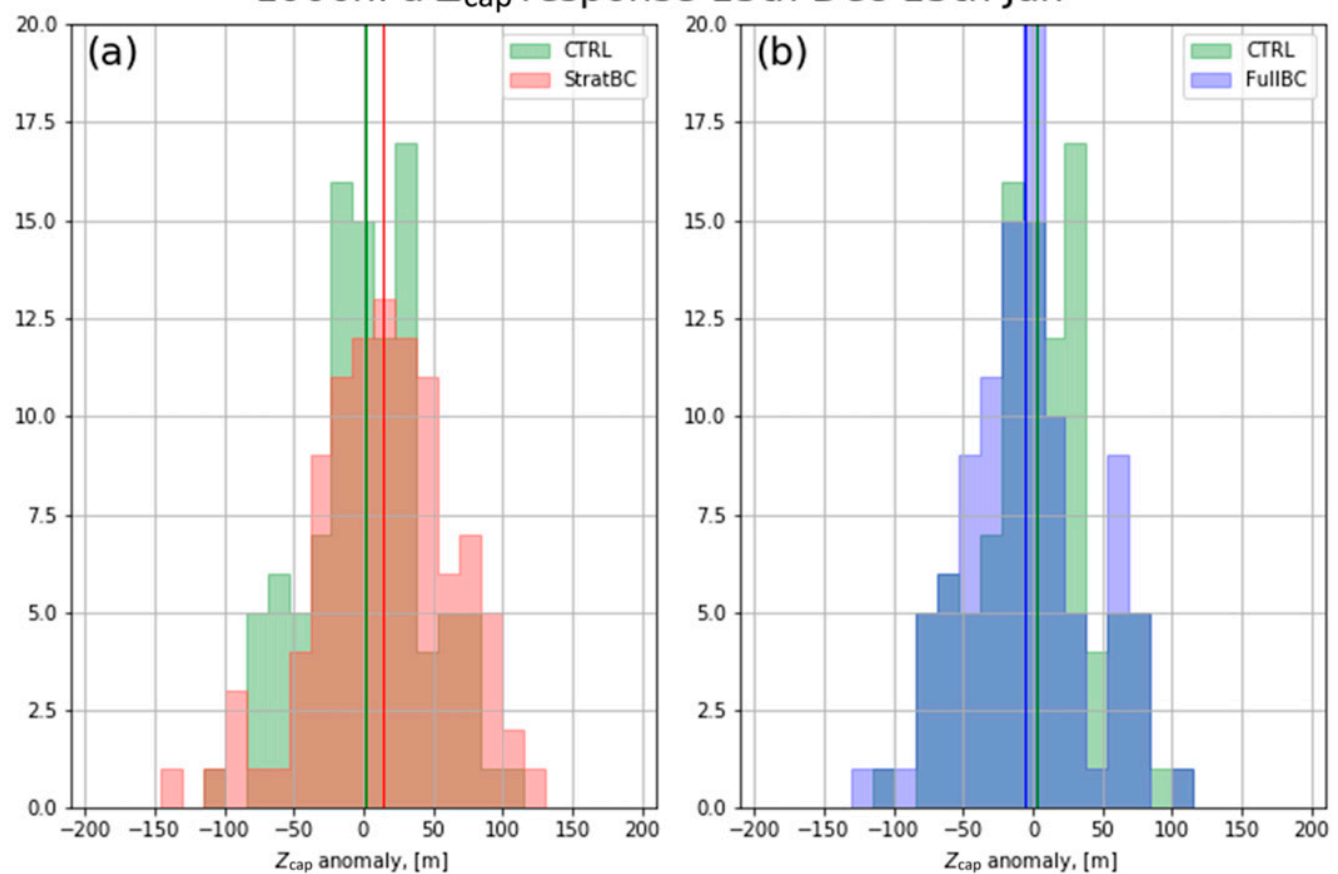

(c)

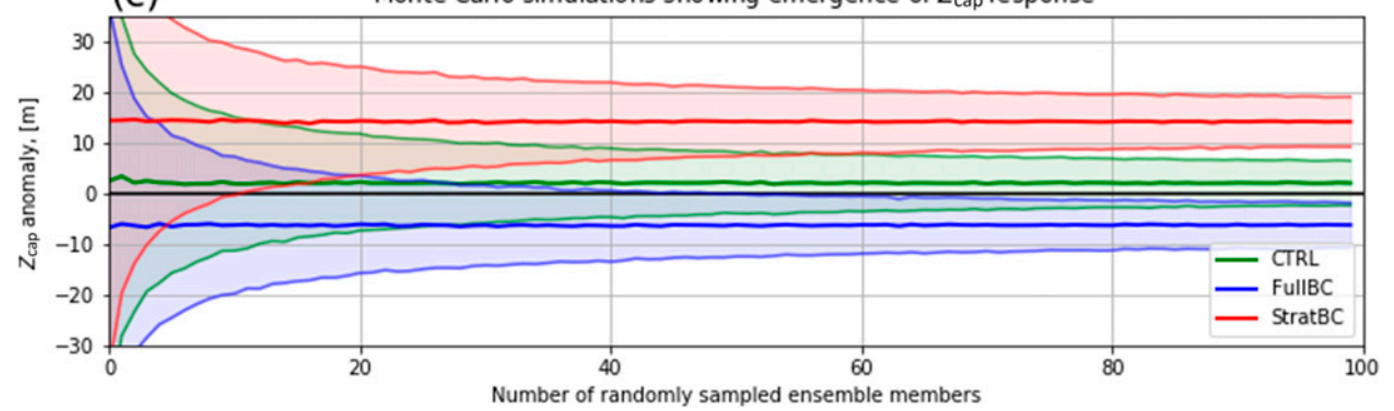

FIG. 5. (a),(b) Histogram of $Z_{\text {cap }}$ response at $1000 \mathrm{hPa}$ :CTRL_SNOW - CTRL (green), StratBC_SNOW StratBC (red), and FullBC_SNOW - FullBC (blue). Vertical lines indicate mean values. (c) Monte Carlo simulations of $Z_{\text {cap }} 1000-\mathrm{hPa}$ snow response for CTRL, FullBC, and StratBC; ensemble was randomly subsampled 5000 times for each number of ensemble members; shading shows one standard deviation.

in StratBC $(p<0.05)$ but not in CTRL, or FullBC (Fig. S2). However, even in StratBC runs the response is still small compared to the variability.

The difference between the surface response to snow across different climatologies during 15 December-15 January is tested with a Kolmogorov-Smirnov test and shown with the histograms in Figs. 5a and 5b. Here we are testing whether there is a significant difference between the snow response in the three climatologies; CTRL, FullBC, and StratBC, with the null hypothesis being that the response of the $1000-\mathrm{hPa}$ polar cap geopotential height to the snow forcing is the same for the three experiments. We choose the period 15 December15 January, since the time series in Fig. 4 indicates the largest difference between the experiments for that time period. We find a significant difference between the response of the StratBC and FullBC experiments at $p<0.05$. For the difference between StratBC and CTRL the $t$ test has a $p$ value $<0.10$, but not $p<0.05$, implying we have up to $10 \%$ probability that the hypothesis is wrong. Considering we are testing the difference of a response we accept the lower significance level in this instance. No significant difference was found between the responses of FullBC and CTRL. During this period, the mean $1000-\mathrm{hPa} Z_{\text {cap }}$ response in FullBC_SNOW is negative, and in StratBC_SNOW is more positive than that in CTRL_SNOW, demonstrating that the strength of the climatological stratospheric vortex, which is roughly similar in FullBC and StratBC, does not strongly affect the stratospheretroposphere coupling in our experiments. The histograms shows the large variability in the surface response compared to the small signal. For example, the mean $Z_{\text {cap }}$ response in FullBC is around $20 \mathrm{~m}$ less than StratBC, which has a standard deviation of $50 \mathrm{~m}$. This shows the importance of large 


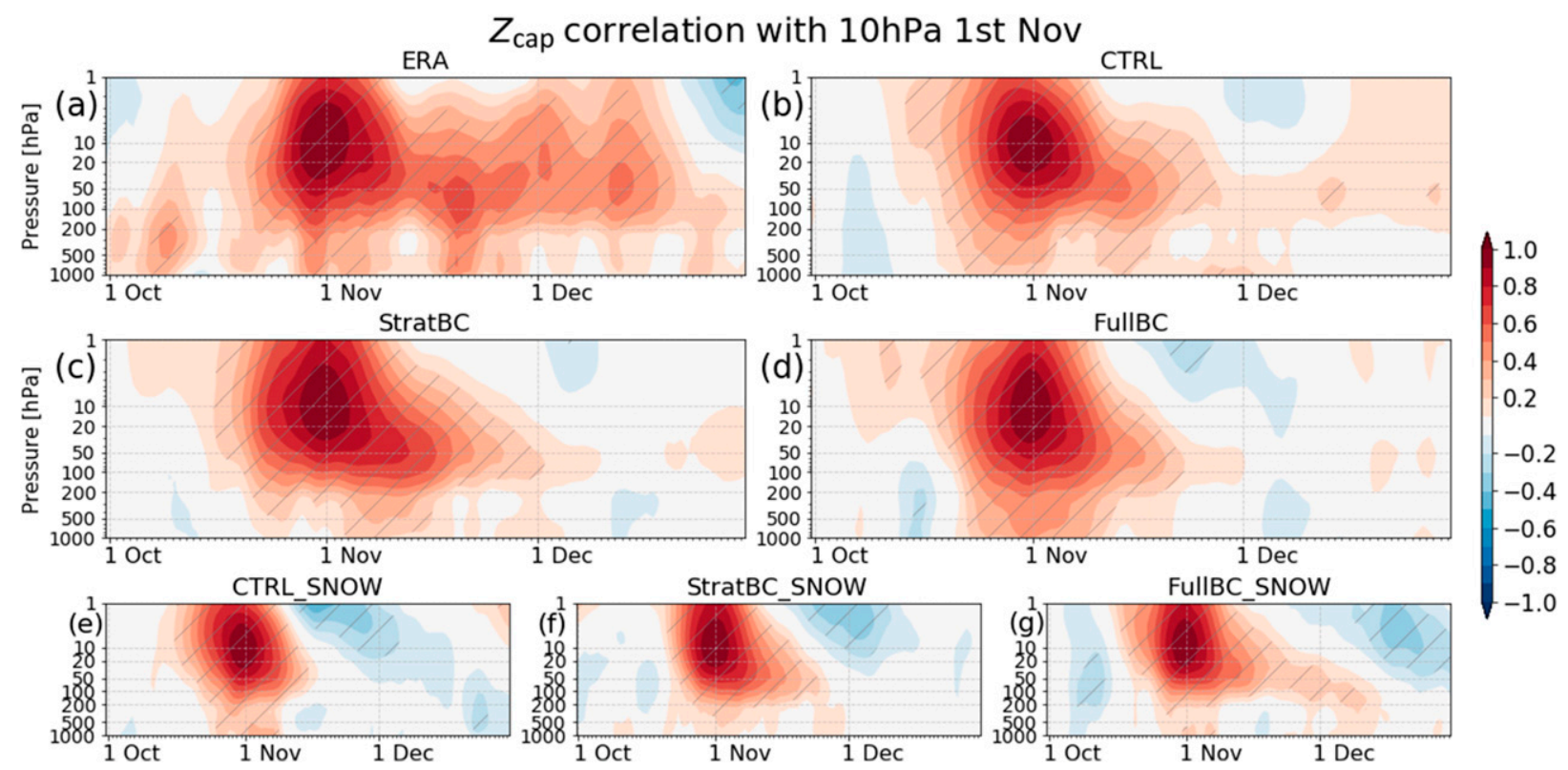

FIG. 6. Correlation of 1 Nov $Z_{\text {cap }}$ at $10 \mathrm{hPa}$, with all levels and days from 1 October to 31 December, for (a) ERA-Interim and (b)-(g) the different model climatologies. Hatching indicates significance: $p<0.05$.

ensembles for seasonal forecasting if this phenomenon is to be captured by models, due to the relatively small changes to the probability distribution of the forecasted climate states. In Fig. 5c we use a Monte Carlo method to test if the number of ensemble members is sufficient for our conclusions. We randomly subsample our simulations, and test the response due to the snow. We ran the test 5000 times for each number of ensemble members (from 1 to 99 subsampled members), and the shading shows the standard deviation from those 5000 tests. It showed that the response had largely stabilized by 80 or 90 members, and additional runs will not change the conclusions.

Now we have determined there are differences in the surface impact between the climatologies, we consider what could be affecting the downward propagation of the stratospheric signal to the surface. In Fig. 6 we test the effect of the bias corrections on downward propagation by correlating the $Z_{\text {cap }}$ at $10 \mathrm{hPa}$ on 1 November with the daily $Z_{\text {cap }}$ at all levels, and show ERAInterim for comparison. As we are interested in the internal dynamics for each experiment, we show the correlation in the control runs and snow anomaly runs separately. The ERA-Interim results in Fig. 6a show the extended stratospheric time scales, with significant correlations extending up to two months. The time scales are shorter in all model runs, extending up to one month. Likewise the stratosphere-to-troposphere signal is stronger in ERA-Interim, but still present in the models. This is consistent with the findings of Gerber et al. (2010), where they found similar results for a range of models (i.e., their Fig. 10). There are differences between the climatologies, where the CTRL and StratBC runs have a slightly longer stratospheric time scale and the downward propagation is delayed compared to the FullBC runs, however, that is not true for the CTRL_SNOW, StratBC_SNOW, and FullBC_SNOW runs. Since snow forcing should not affect stratospheric time scales, which are controlled by radiative processes (Hitchcock and Shepherd 2013), the differences between model climatologies are not systematic and likely due to internal variability. We conclude that the time scales of stratospheric variability are shorter in the model than in observations, and there is weaker downward coupling, but this is not significantly affected by the bias corrections.

The persistence of the lower-stratospheric NAM is important for the tropospheric response to SSWs (e.g., Maycock and Hitchcock 2015). This is tested in Fig. S3, which shows the lagged relationship between October-November $Z_{\text {cap }}$ at $100 \mathrm{hPa}$ and 15 November-15 December $Z_{\text {cap }}$ at $1000 \mathrm{hPa}$. We find a similar relationship between the experiments, implying that the bias corrections do not alter the persistence or stratosphere-troposphere connection. Hence, the lack of a surface signal in the FullBC_ SNOW experiment is not due to the bias corrections preventing downward propagation of the stratospheric signal. The latitude of the tropospheric jet has been shown to influence stratospheretroposphere coupling (Garfinkel et al. 2013), so the influence of the jet position in the North Atlantic and North Pacific was tested. The FullBC run tended to be closer to ERA-Interim in magnitude and latitude, as expected. However, the latitudinal differences between the runs were around $1^{\circ}-2^{\circ}$, too small to explain the differences in the snow response (not shown).

The monthly progression of the surface pressure response is shown in Fig. 7, for the CTRL_SNOW (Figs. 7a-d), StratBC_ SNOW (Figs. 7e-h), and FullBC_SNOW (Figs. 7i-l), and as a comparison to observations we show a regression between October Siberian 2-m temperature and surface pressure using ERA-Interim data (Figs. 7m-p), following Tyrrell et al. (2019). First, we look at the differences between model and observations. In October and into November the ERA-Interim regressions show high pressure over northern Eurasia. This pressure field is consistent with cold Siberian temperatures and increased snow extent (e.g., Tyrrell 


\section{SLP response to Siberian snow}

(a) CTRL, Oct

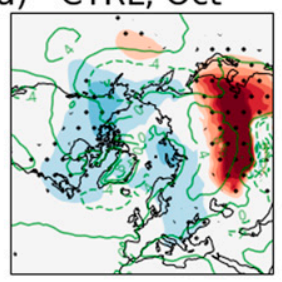

(e) StratBC, Oct

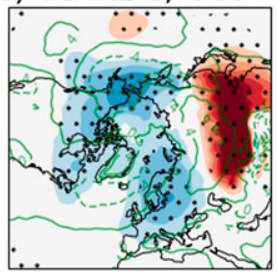

(i) FullBC, Oct

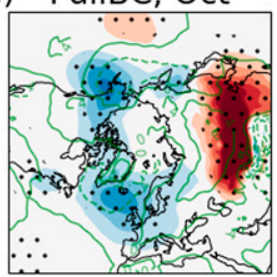

(m) ERAi, Oct

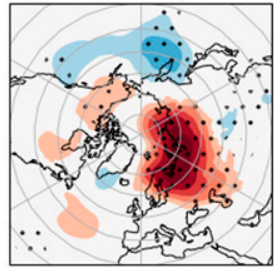

(b) CTRL, Nov

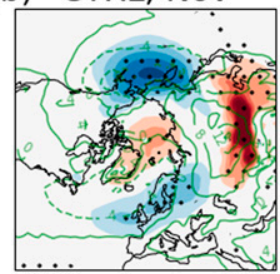

(f) StratBC, Nov

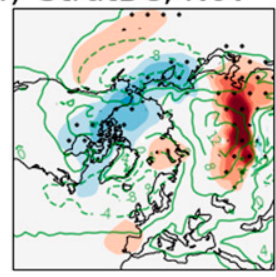

(j) FullBC, Nov

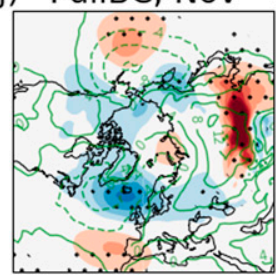

(n) ERAi, Nov

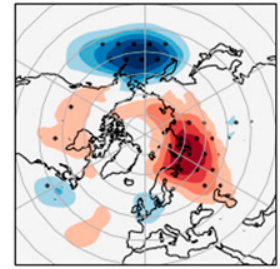

(c) CTRL, Dec

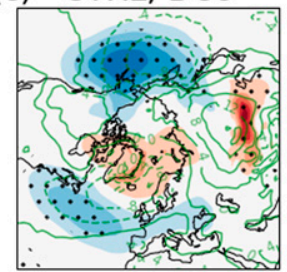

(g) StratBC, Dec

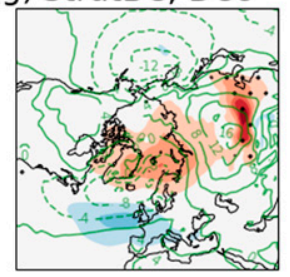

(k) FullBC, Dec

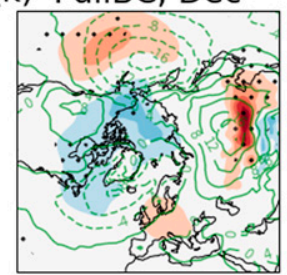

(o) ERAi, Dec

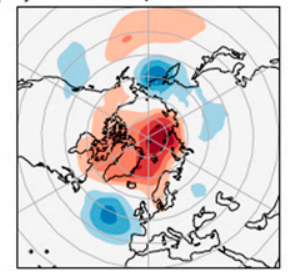

(d) CTRL, Jan

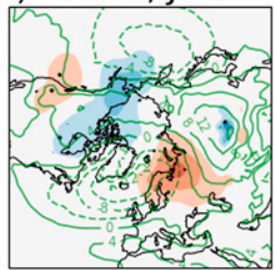

(h) StratBC, Jan

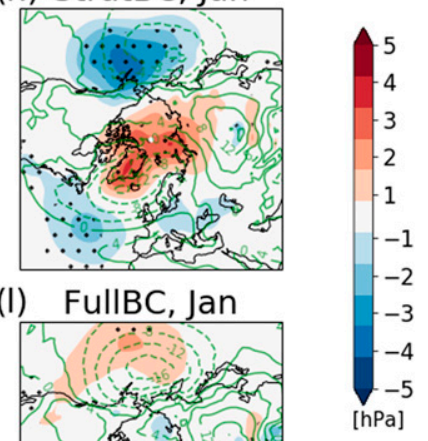

FIG. 7. Mean sea level pressure response to snow anomaly in the (a)-(d) CTRL, (e)-(h) StratBC, and (i)-(l) FullBC experiments, for October to January. Gray contours show monthly climatological MSLP with zonal mean removed. $(\mathrm{m})-(\mathrm{p})$ A regression between October Siberian 2-m temperature $\left(40^{\circ}-60^{\circ} \mathrm{N}, 60^{\circ}-140^{\circ} \mathrm{E}\right)$ and surface pressure for October-December, using ERA-Interim data from 1979 to 2016. Stippling indicates significance: $p<0.05$.

et al. 2019). The October and November pressure anomalies in the snow perturbation experiments are different, with a high pressure anomaly farther south and east. The higher pressure in eastern and central Asia is a direct response to the surface cooling due to the snow anomaly: a thermal anticyclone that is aligned with the strongest cooling.

Focusing now on the evolution of pressure anomalies in the perturbation runs, in the CTRL_SNOW run a negative AO develops in November and persists into December, with a significant deepening of the Aleutian low and a weak polar response, then there is little significant response in January. In the StratBC_SNOW run a negative AO develops in December and then strengthens into January, with significant polar and midlatitude SLP anomalies. During October and November in the FullBC runs there is a negative anomaly in the North Atlantic, and the Aleutian low weakens. November has some zonal asymmetries, but a strong positive NAO is present, then a positive AO develops in December, before fading in
January. The positive NAO pattern in November may have played a role in preventing the downward propagation of the stratospheric signal in the FullBC runs. We tested this by subsampling the results and conditioning on positive November NAO (shown in Fig. S4). It was found that a positive NAO pattern in the CTRL and StratBC experiments did not lead to a reduction in downward propagation. Further, when conditioned on a positive NAO and a weak vortex (i.e., attempting to maximize the stratospheric signal by removing years without a strong stratospheric signal, not shown), the FullBC experiment showed some weak downward propagation, implying that a positive NAO does not prevent downward propagation in the CTRL and StratBC experiments, or when there is a strong enough weakening of the stratospheric vortex in the FullBC experiment. Both these results indicate that a positive NAO pattern alone is not sufficient to prevent downward propagation. Given a major difference between the FullBC, and CTRL and StratBC climatologies was the tropospheric adjustment to the snow forcing, it seems likely that 
this contributed to the lack of propagation; however, the exact mechanism is not clear.

Finally, we looked at the delayed Eurasian 2-m temperature response to snow forcing, which may be associated with a negative AO response in sea level pressure fields (e.g., Butler et al. 2019). November, December, and January temperature fields were tested and no significant delayed response was present for any of the experiments, likely due to the weak pressure response and because of the damping effect of the climatological SSTs used in the experiments.

\section{Conclusions}

In this study we have used a novel bias correction technique to simulate different background climatologies in the atmosphereonly model ECHAM6, and in particular significantly reduced errors in the simulated stratospheric polar vortex present in the control model version. The bias correction technique artificially reduces errors in the model's wind and pressure fields, while allowing the model to freely respond to perturbations. Two different sets of experiments were performed in which bias corrections were applied to the troposphere and stratosphere or to the stratosphere only. A Siberian snow extent anomaly was introduced to test the response of the model to a surface perturbation within the different climatologies. The snow anomaly induced a weakened stratospheric polar vortex from October to December in the three climatologies, with the magnitude of the weakening having no clear dependence on the strength of the climatological vortex. We found the strongest surface response to the weakened stratospheric vortex in the model with a biascorrected stratosphere (i.e., no tropospheric bias corrections), where the snow anomaly and weakened vortex induced a surface pressure response that was similar in sign and area to the control run but stronger. In contrast, the model with bias corrections in the troposphere and stratosphere had no significant surface response, and downward propagation of the stratospheric signal was suppressed.

The initial response in October to the snow anomaly was similar among the three experiments, showing a strong high pressure over the snow region balanced with low pressure over North America, the North Pacific, and Europe (CTRL and StratBC), or the North Pacific and North Atlantic (FullBC), a strengthening of the climatological wavenumber 1 , an increase in $\mathrm{HF}$ at $100 \mathrm{hPa}$, and a subsequent weakening of stratospheric zonal winds from mid-October. Moving into November, the three experiments still show many similarities. Most notably is the similar magnitude of the decrease in the polar vortex, notable since there is a large discrepancy between the strength of the vortex between the three control runs. The FullBC and StratBC runs had $\mathrm{uz}_{60 \mathrm{~N}}$ about $10 \mathrm{~m} \mathrm{~s}^{-1}$ greater than CTRL (75\% reduction in the bias) yet the anomalous decrease in the snow runs was very similar. Hence, the magnitude of the stratospheric wind anomaly is not dependent on the strength of the polar winds. The polar vortex response is further elucidated in the daily $Z_{\text {cap }}$, where we see the stratospheric geopotential height response in StratBC and FullBC runs is also delayed compared to the CTRL runs; however, the subsequent anomaly is of comparable magnitude. This result differs somewhat from those of Fletcher et al. (2009) (i.e., their Fig. 10), where an initially weaker vortex is associated with a stronger stratospheric geopotential height anomaly.

As the anomalies progress into November and December some differences emerge. Although the differences are small relative to variability, we see a lack of downward propagation in the FullBC runs compared to a significant downward propagation in the StratBC runs in December and January, leading to a negative AO signal in early January. From the time series of HF (Fig. 2b) it would seem that the persistence of tropospheric anomalies to an October Siberian snow forcing is necessary for a sustained stratospheric response, and the sustained stratospheric response leads to a strong surface response in December-January. The persistence of the stratospheric anomalies and subsequent downward propagation in the model has shorter stratospheric time scales than observations, but they are not greatly affected by the bias corrections.

A number of factors that could explain differences in downward propagation were tested, such as the jet latitude in the North Atlantic (e.g., Garfinkel et al. 2013), the phase of the climatological and anomalous waves, and the role of a persistent positive NAO, but these were also found to not be significantly affected by the bias corrections. Hence, some other dynamical process, which we cannot identify, must be responsible for the difference in downward propagation between the StratBC and the FullBC and CTRL runs.

Further, there was no significant delayed European temperature response for any of the experiments; that is, October Siberian temperatures and November, December, or January European temperatures show no correlation. We note that since our experiments use fixed SSTs this may dampen the surface temperature response. Regardless, given the lack of a delayed temperature response to such a strong surface forcing, our results further question the usefulness of Eurasian snow cover as a single predictor for seasonal forecasting.

The snow perturbation experiments have limitations that may affect the responses. The pressure fields in Fig. 7 demonstrate a major discrepancy between our perturbation runs and nature. In nature, the snow anomaly is the result of large-scale dynamics and is consistent with the large-scale fields, whereas in our runs we impose snow and then we study the response. Thus, the snow anomaly is inconsistent with initial dynamical fields. A snow extent anomaly may be an important seasonal predictor because it amplifies the larger atmospheric conditions that result in a weakened stratospheric vortex, but alone it may not be a strong enough to consistently overcome the large wintertime variability and hence impact wintertime surface temperatures. Although our experiments are unable to test for this amplification, they do allow us to single out the effect of the snow on the atmosphere. Once we have isolated that effect, we then test the influence of model biases on the response. The difference in the pressure fields between observations and the experiments is clear in October, yet the perturbations generate a significant upward wave flux. A more realistic large-scale circulation may have affected the magnitude of the upward wave flux, but given that it is similar between the three climatologies this does not appear to be related to model biases. Experiments accounting for pre-existing circulation anomalies during years with large snow cover may be required to 
fully understand the impact of the Siberian snow extent on the wintertime circulation.

Correct representation of teleconnections, including those that act through the modulation of the polar stratospheric vortex such as the October Siberian snow-AO connection, are necessary for skillful seasonal forecasts. We have shown that dynamical bias correction can lead to a different surface response to Siberian snow cover, and hence model biases likely influence the skill of seasonal forecasts. While we find the differences due to bias corrections are small, we note that it may be due to the fact that the forcing is relatively weak. Further work is underway to test how bias corrections affect other teleconnections known to contribute to seasonal forecast skill, such as El Niño and the QBO. A broader question remains about the usefulness of this technique for seasonal forecasting. The different responses between the bias-corrected runs indicate the difficulty in using this method for operational forecasting; however, a greater understanding of the role of biases may shed light on the areas of focus for model development.

Acknowledgments. The authors would like to acknowledge John Scinocca, Slava Kharin, and Michael Sigmond for invaluable technical and scientific help at the outset of this project. Thoughtful and thorough reviews from three anonymous reviewers greatly improved the manuscript. N. T. and A. Y. K. are funded by the Academy of Finland (Grants 286298 and 294120, respectively). ERA-Interim data are available from http://www.ecmwf.int. The ECHAM6 model is available to the scientific community under a version of the MPI-M license http://www.mpimet.mpg.de/en/science/models/license/. The HadISST SST and sea ice data are available from the U.K. Met Office https://www.metoffice.gov.uk/hadobs/hadisst/. Data for the ECHAM6 simulations are available from Nicholas Tyrrell upon request.

\section{REFERENCES}

Allen, R. J., and C. S. Zender, 2010: Effects of continental-scale snow albedo anomalies on the wintertime Arctic oscillation. J. Geophys. Res., 115, D23105, https://doi.org/10.1029/2010JD014490.

Baldwin, M. P., and T. J. Dunkerton, 2001: Stratospheric harbingers of anomalous weather regimes. Science, 294, 581-584, https://doi.org/10.1126/science.1063315.

Birner, T., and J. R. Albers, 2017: Sudden stratospheric warmings and anomalous upward wave activity flux. SOLA, 13A , 8-12, https://doi.org/10.2151/sola.13A-002.

Butler, A., and Coauthors, 2019: Sub-seasonal predictability and the stratosphere. Sub-Seasonal to Seasonal Prediction: The Gap Between Weather and Climate Forecasting, Elsevier, 223241, https://doi.org/10.1016/B978-0-12-811714-9.00011-5.

Chang, Y., S. D. Schubert, R. D. Koster, A. M. Molod, and H. Wang, 2019: Tendency bias correction in coupled and uncoupled global climate models with a focus on impacts over North America. J. Climate, 32, 639-661, https://doi.org/10.1175/JCLI-D-18-0598.1.

Cohen, J., and C. Fletcher, 2007: Improved skill of Northern Hemisphere winter surface temperature predictions based on land atmosphere fall anomalies. J. Climate, 20, 4118-4132, https://doi.org/10.1175/JCLI4241.1.

— , M. Barlow, P. J. Kushner, and K. Saito, 2007: Stratospheretroposphere coupling and links with Eurasian land surface variability. J. Climate, 20, 5335-5343, https://doi.org/10.1175/ 2007JCLI1725.1.

_, J. Foster, M. Barlow, K. Saito, and J. Jones, 2010: Winter 2009-2010: A case study of an extreme Arctic Oscillation event. Geophys. Res. Lett., 37, L17707, https://doi.org/10.1029/ 2010 GL044256.

— treme mid-latitude weather. Nat. Geosci., 7, 627-637, https:// doi.org/10.1038/ngeo2234.

Dee, D. P., and Coauthors, 2011: The ERA-Interim reanalysis: Configuration and performance of the data assimilation system. Quart. J. Roy. Meteor. Soc., 137, 553-597, https://doi.org/ 10.1002/qj.828.

de la Cámara, A., J. R. Albers, T. Birner, R. R. Garcia, P. Hitchcock, D. E. Kinnison, and A. K. Smith, 2017: Sensitivity of sudden stratospheric warmings to previous stratospheric conditions. J. Atmos. Sci., 74, 2857-2877, https:// doi.org/10.1175/JAS-D-17-0136.1.

Douville, H., Y. Peings, and D. Saint-Martin, 2017: Snow-(N)AO relationship revisited over the whole twentieth century. Geophys. Res. Lett., 44, 569-577, https://doi.org/10.1002/2016GL071584.

Eden, J. M., M. Widmann, D. Grawe, and S. Rast, 2012: Skill, correction, and downscaling of GCM-simulated precipitation. J. Climate, 25, 3970-3984, https://doi.org/10.1175/JCLI-D-1100254.1.

Fletcher, C. G., P. J. Kushner, and J. L. Cohen, 2007: Stratospheric control of the extratropical circulation response to surface forcing. Geophys. Res. Lett., 34, L21802, https://doi.org/10.1029/ 2007GL031626.

— , S. C. Hardiman, P. J. Kushner, and J. L. Cohen, 2009: The dynamical response to snow cover perturbations in a large ensemble of atmospheric GCM integrations. J. Climate, 22, 1208-1222, https://doi.org/10.1175/2008JCLI2505.1.

Furtado, J. C., J. L. Cohen, A. H. Butler, E. E. Riddle, and A. Kumar, 2015: Eurasian snow cover variability and links to winter climate in the CMIP5 models. Climate Dyn., 45, 25912605, https://doi.org/10.1007/s00382-015-2494-4.

Garfinkel, C. I., D. W. Waugh, and E. P. Gerber, 2013: The effect of tropospheric jet latitude on coupling between the stratospheric polar vortex and the troposphere. J. Climate, 26, 20772095, https://doi.org/10.1175/JCLI-D-12-00301.1.

Gerber, E. P., C. Orbe, and L. M. Polvani, 2009: Stratospheric influence on the tropospheric circulation revealed by idealized ensemble forecasts. Geophys. Res. Lett., 36, L24801, https:// doi.org/10.1029/2009GL040913.

_ nular mode variability in chemistry-climate models. J. Geophys. Res., 115, D00M06, https://doi.org/10.1029/2009JD013770.

Gong, G., D. Entekhabi, and J. L. Cohen, 2002: A large-ensemble model study of the wintertime AO-NAO and the role of interannual snow perturbations. J. Climate, 15, 3488-3499, https://doi.org/10.1175/ 1520-0442(2002)015<3488:ALEMSO>2.0.CO;2.

Hardiman, S. C., P. J. Kushner, and J. L. Cohen, 2008: Investigating the ability of general circulation models to capture the effects of Eurasian snow cover on winter climate. J. Geophys. Res., 113, D21123, https://doi.org/10.1029/2008JD010623.

Henderson, G. R., Y. Peings, J. C. Furtado, and P. J. Kushner, 2018: Snowatmosphere coupling in the Northern Hemisphere. Nat. Climate Change, 8, 954-963, https://doi.org/10.1038/s41558-018-0295-6.

Hitchcock, P., and T. G. Shepherd, 2013: Zonal-mean dynamics of extended recoveries from stratospheric sudden warmings. J. Atmos. Sci., 70, 688-707, https://doi.org/10.1175/JAS-D-120111.1. 
Karpechko, A. Y., P. Hitchcock, D. H. W. Peters, and A. Schneidereit, 2017: Predictability of downward propagation of major sudden stratospheric warmings. Quart. J. Roy. Meteor. Soc., 143, 1459-1470, https://doi.org/10.1002/qj.3017.

Kharin, V. V., and J. F. Scinocca, 2012: The impact of model fidelity on seasonal predictive skill. Geophys. Res. Lett., 39, L18803, https://doi.org/10.1029/2012GL052815.

Kretschmer, M., D. Coumou, J. F. Donges, and J. Runge, 2016: Using causal effect networks to analyze different Arctic drivers of midlatitude winter circulation. J. Climate, 29, 40694081, https://doi.org/10.1175/JCLI-D-15-0654.1.

Maycock, A. C., and P. Hitchcock, 2015: Do split and displacement sudden stratospheric warmings have different annular mode signatures? Geophys. Res. Lett., 42, $10943-10$ 951, https:// doi.org/10.1002/2015GL066754.

Newman, P. A., E. R. Nash, and J. E. Rosenfield, 2001: What controls the temperature of the Arctic stratosphere during the spring? J. Geophys. Res., 106, 19 999-20 010, https://doi.org/ 10.1029/2000JD000061.

Orsolini, Y. J., R. Senan, F. Vitart, G. Balsamo, A. Weisheimer, and F. J. Doblas-Reyes, 2016: Influence of the Eurasian snow on the negative North Atlantic Oscillation in subseasonal forecasts of the cold winter 2009/2010. Climate Dyn., 47, 13251334, https://doi.org/10.1007/s00382-015-2903-8.

Peings, Y., 2019: Ural blocking as a driver of early winter stratospheric warmings. Geophys. Res. Lett., 46, 5460-5468, https:// doi.org/10.1029/2019GL082097.

Plumb, R. A., 1985: On the three-dimensional propagation of stationary waves. J. Atmos. Sci., 42, 217-229, https://doi.org/ 10.1175/1520-0469(1985)042<0217:OTTDPO > 2.0.CO;2.

Rayner, N. A., D. E. Parker, E. B. Horton, C. K. Folland, L. V. Alexander, D. P. Rowell, E. C. Kent, and A. Kaplan, 2003: Global analyses of sea surface temperature, sea ice, and night marine air temperature since the late nineteenth century. J. Geophys. Res., 108, 4407, https://doi.org/10.1029/2002JD002670.

Schubert, S. D., Y. Chang, H. Wang, R. D. Koster, and A. M. Molod, 2019: A systematic approach to assessing the sources and global impacts of errors in climate models. J. Climate, 32, 8301-8321, https://doi.org/10.1175/JCLI-D-19-0189.1.

Schubert-Frisius, M., F. Feser, H. von Storch, and S. Rast, 2017: Optimal spectral nudging for global dynamic downscaling. Mon. Wea. Rev., 145, 909-927, https://doi.org/10.1175/MWR-D-16-0036.1.
Simpson, I. R., P. Hitchcock, T. G. Shepherd, and J. F. Scinocca, 2013a: Southern annular mode dynamics in observations and models. Part I: The influence of climatological zonal wind biases in a comprehensive GCM. J. Climate, 26, 3953-3967, https://doi.org/10.1175/JCLI-D-12-00348.1.

—, T. G. Shepherd, P. Hitchcock, and J. F. Scinocca, 2013b: Southern annular mode dynamics in observations and models. Part II: Eddy feedbacks. J. Climate, 26, 5220-5241, https:// doi.org/10.1175/JCLI-D-12-00495.1.

Smith, K. L., C. G. Fletcher, and P. J. Kushner, 2010: The role of linear interference in the annular mode response to extratropical surface forcing. J. Climate, 23, 6036-6050, https:// doi.org/10.1175/2010JCLI3606.1.

— , P. J. Kushner, and J. L. Cohen, 2011: The role of linear interference in northern annular mode variability associated with Eurasian snow cover extent. J. Climate, 24, 6185-6202, https://doi.org/10.1175/JCLI-D-11-00055.1.

Stevens, B., and Coauthors, 2013: Atmospheric component of the MPIM Earth system model: ECHAM6. J. Adv. Model. Earth Syst., 5, 146-172, https://doi.org/10.1002/jame.20015.

Tripathi, O. P., and Coauthors, 2016: Examining the predictability of the stratospheric sudden warming of January 2013 using multiple NWP systems. Mon. Wea. Rev., 144, 1935-1960, https://doi.org/10.1175/MWR-D-15-0010.1.

Tyrlis, E., E. Manzini, J. Bader, J. Ukita, H. Nakamura, and D. Matei, 2019: Ural blocking driving extreme Arctic sea ice loss, cold Eurasia and stratospheric vortex weakening in autumn and early winter 2016-2017. J. Geophys. Res. Atmos., 124, 11313-11329, https://doi.org/10.1029/2019JD031085.

Tyrrell, N. L., A. Y. Karpechko, and P. Räisänen, 2018: The influence of Eurasian snow extent on the northern extratropical stratosphere in a QBO resolving model. J. Geophys. Res., 123, 315-328, https://doi.org/10.1002/2017JD027378.

,,-- P. Uotila, and T. Vihma, 2019: Atmospheric circulation response to anomalous Siberian forcing in October 2016 and its long-range predictability. Geophys. Res. Lett., 46, 28002810, https://doi.org/10.1029/2018GL081580.

White, I., C. I. Garfinkel, E. P. Gerber, M. Jucker, V. Aquila, and L. D. Oman, 2019: The downward influence of sudden stratospheric warmings: Association with tropospheric precursors. J. Climate, 32, 85-108, https://doi.org/10.1175/JCLID-18-0053.1. 